\title{
Conexões
}

\section{Educación Física y Praxiología Motriz}

Pierre Parlebas ${ }^{1}$

\section{RESUMEN}

El punto de partida es un breve análisis de los problemas a los cuales se enfrenta la Educación Física, de los diferentes aspectos de la crisis y el señalamiento de cuáles han sido las respuestas clásicas y conservadoras, frente a todo ello. En ese marco, se reivindica la necesidad de una ciencia de la acción motriz o praxiología motriz. La Educación Física es una práctica de intervención educativa que puede ser esclarecida a través de procesos científicos. Mediante el concepto conducta motriz ubicamos al ser que se mueve, y no al movimiento o al cuerpo, en el centro del acto educativo. Aportando a las diferentes dimensiones de la personalidad humana, esta perspectiva permite situar a la Educación Física dentro del campo educativo. Al momento de proponer situaciones motrices el docente deberá tener en cuenta la lógica interna de las prácticas y los dominios de acción motriz. Se concluye que la praxiología motriz no debe ser confundida con la Educación Física, pero sí puede arrojar luz respecto a la coherencia y a la adecuación de las prácticas a los efectos educativos buscados, todo ello en una constante ida y vuelta entre la reflexión teórica y la realización práctica.

Palabras clave: Educación Física. Acción motriz. Conducta motriz. Epistemología. Ciencia.

\footnotetext{
1 Université Paris V.
}

Correspondência:

Pierre Parlebas. Université de Paris. UFR STTAPS, 1 rue Lacretelle 75015 Paris, França, Email: pparlebas@gmail.com 


\section{Educação Física e Praxiologia Motriz}

\section{RESUMO}

O ponto de partida deste texto é uma breve análise dos problemas que a Educação Física enfrenta, dos diferentes aspectos da crise e a indicação de quais têm sido as respostas clássicas e conservadoras a tudo isso. Nesta estrutura, é reivindicada a necessidade de uma ciência da ação motriz ou da praxiologia motriz. A Educação Física é uma prática de intervenção educativa que pode ser esclarecida através de processos científicos. Considerando o conceito de conduta motriz é que localizamos o ser que se move, e não o movimento ou o corpo, no centro do ato educativo. Contribuindo para as diferentes dimensões da personalidade humana, essa perspectiva permite colocar a Educação Física no campo educacional. Ao propor situações motrizes, o professor deve levar em consideração a lógica interna das práticas e os domínios de ação motriz. Conclui-se que a praxiologia motriz não deve ser confundida com a Educação Física, mas pode lançar luz sobre (ou elucidar) a coerência e adaptação das práticas aos efeitos educacionais pretendidos, tudo em constante ida e volta entre reflexão teórica e realização prática.

Palavras-chave: Educação física. Ação motriz. Conduta motriz. Epistemologia. Ciência.

\section{Physical Education and Motor Praxeology}

\section{ABSTRACT}

The starting point is a brief analysis of the problems that Physical Education faces, including the different aspects of the crisis and the indication of what have been the classic and conservative answers to all this. In this framework, the need for a science of motor action or motor praxeology is claimed. Physical Education is an educational intervention practice what can be clarified through scientific processes. Through the concept of motor behaviour we place the human being that moves, and not the movement or the body, at the center of the educational act. Contributing to the different dimensions of the human personality, this perspective allows Physical Education to be placed in the educational field. When motor situations are propose, the teacher must consider the internal logic of the practices and the domains of motor action. In conclusion, motor praxeology should not be confused with Physical Education, but it can shed light on the coherence and adaptation of practices to the intended educational goals, all in a constant round trip between theoretical reflection and practical realization.

Keywords: Physical education. Motor action. Motor conduct. Epistemology. Science. 


\section{LA CONSTATACIÓN DE UNA CRISIS}

¿La Educación Física (EF) ocupa un lugar propio en la educación? ¿Acaso está inscripta en un campo científico creíble?

Se impone una primera constatación: en numerosos países, la EF se encuentra en crisis, así lo indica During (1992) en su libro "La crisis de las pedagogías corporales". Se trata de una crisis de identidad: ¿Qué es la EF? ¿Tiene un objeto propio?

Se constata que dos principales peligros amenazan a la EF:

1) La atomización; la EF está fragmentada, dispersa:

- en innumerables técnicas: existen cientos de especialidades deportivas y de juegos: el atletismo, los deportes colectivos, los deportes en contacto con la naturaleza, los juegos tradicionales, etc.

- en múltiples campos de intervención: el mundo de la educación, de la rehabilitación, del ocio, del alto rendimiento.

- en numerosos métodos y doctrinas: la psicocinética, la Educación Nueva, los métodos constructivistas, el yoga, la eutonía, los métodos deportivos, etc.

¿Qué es lo que puede unir estos conjuntos tan heterogéneos?

2) La dependencia:

Actualmente la EF se encuentra bajo la dependencia teórica de las disciplinas científicas clásicas: la biomecánica, la psicología, la sociología, etc., y sometida a puntos de vista externos.

Se suele proclamar que se trata de un estudio multidisciplinario muy positivo. En realidad, el estudiante se encuentra frente a una yuxtaposición de puntos de vista heterogéneos, incapaces de establecer una coherencia entre sí. ¿Es inevitable entonces el fracaso?

\section{LA RESPUESTA CLÁSICA}

La respuesta habitual es decididamente conservadora; hay que mantener y desarrollar los aspectos pluridisciplinarios: las actividades físicas y deportivas son un punto de encuentro donde las ciencias pueden encontrarse. Este enfoque no aporta nada nuevo y sólo estanca a la EF en una categoría de dependencia y 
de inferioridad.

Numerosos autores desean fundamentar la EF en una ciencia del movimiento. Sin embargo, el "movimiento" es un concepto de la ciencia física y significa un desplazamiento en el espacio. Se habla del movimiento de los planetas, del movimiento de la marea. El campeón del movimiento es Newton. ¿Acaso la EF es un subproducto de la física de Isaac Newton?

Actualmente "el cuerpo" está de moda. Por supuesto, las sensaciones del cuerpo, la vivencia corporal, la corporeidad son fenómenos importantes; pero en el marco de la EF, adquieren sentido sólo dentro de la conducta motriz.

Parece vano yuxtaponer comparando entre sí, a las múltiples teorías del cuerpo, porque el cuerpo de Merleau-Ponty (1993) no tiene mucho que ver con el cuerpo del biomecanicista, con el cuerpo de Foucault (1976) o con el de Bourdieu (1988). Se encuentra allí una asombrosa ilusión epistemológica que se nutre de la polisemia del término "cuerpo".

\section{UNA RESPUESTA MODERNA: LA CIENCIA DE LA ACCIÓN MOTRIZ}

No se trata de una doctrina, sino de una problemática que se plantea en nuevos términos.

Este nuevo paradigma ubica en la base de sus análisis a la «conducta motriz» de cada individuo. Esta conducta se asocia con otras conductas para producir una "acción motriz", concepto que se relaciona sobre todo con la acción de un grupo o de un equipo. Recordemos que una conducta motriz es también una acción motriz. Haremos referencia entonces, no a una ciencia de las conductas motrices (lo cual sería demasiado psicologista), sino a una ciencia de la acción motriz o "praxiología motriz".

La EF no es una ciencia sino una práctica de intervención que busca ejercer una influencia relacionada con objetivos educativos. No es una ciencia, pero puede ser esclarecida a través de procesos y resultados científicos.

La EF puede ser definida como una pedagogía de las conductas motrices. Coloca al niño y a sus conductas motrices en el centro del acto educativo. Por lo tanto, una ciencia de la acción motriz se encuentra en una posición ideal para aclararla y explicarla.

Lo que es central para la EF, no es el "movimiento", no es el "cuerpo", es la "conducta motriz" concreta de cada niño, enriquecida por su vivencia corporal. 
No es el movimiento lo que cuenta, sino el ser que se mueve, tal como lo han demostrado en sus trabajos Lavega (2011) y Lagardera (2011).

Los análisis de la praxiología motriz proponen un cambio de paradigma que atribuye a la teoría y a la práctica de la EF características innovadoras:

- una identidad: de allí en más la EF está claramente definida; se sabe en qué consiste;

- una unidad: la atomización deviene en una ventaja, denotando una gran diversidad que se reagrupa bajo un denominador común: la acción motriz;

- una especificidad: el objeto «acción motriz» no es reivindicado por ninguna otra disciplina. La praxiología motriz y la EF no pisan otro territorio; ellas tienen su propio objeto (eliminando así las dañinas rivalidades);

- una cientificidad: la acción motriz puede ser observada, tratada e interpretada como cualquier otro hecho que interesa a las disciplinas científicas. Por lo tanto, los métodos de la investigación pueden ser implementados de manera clara y rigurosa, en el estudio de las situaciones motrices.

\section{CONDUCTA MOTRIZ Y DIMENSIONES DE LA PERSONALIDAD}

¿Acaso esta importancia fundamental atribuida a la conducta motriz aporta modificaciones profundas? ¿Permite situar definitivamente a la EF dentro del campo educativo?

Hoy, gracias a los trabajos de una multiplicidad de disciplinas científicas (biología, psicología del niño, sociología, psicoanálisis, neurología, etc.), sabemos que toda la personalidad del niño está involucrada en el momento en que éste entra en acción. El ser que actúa es tan auténtico y complejo como el ser que habla. La acción motriz es tan importante como el verbo, en un proceso educativo que apunta a influir profundamente en el individuo.

Recordemos muy rápidamente las diferentes dimensiones de la personalidad que requieren las conductas motrices, a saber:

- orgánica: este aspecto es el que ha sido el mejor estudiado desde hace varios siglos;

- cognitiva: las conductas motrices pueden poner en juego una verdadera inteligencia motriz (apreciación de los espacios, de las velocidades, de los cruces, de las anticipaciones, etc.);

- afectiva: la actividad física y deportiva desencadena cambios afectivos. El 
deporte es emoción. La afectividad es la clave de las conductas motrices.

- relacional: las situaciones motrices ofrecen oportunidades de encuentro, de enfrentamientos, de ayuda recíproca. La interacción motriz suele estar en el centro de los intercambios y suscita una sociomotricidad muy intensa con compañeros o contra los adversarios. La dinámica de grupo de tipo sociomotriz es muy diversificada y rica en consecuencias educativas.

- expresiva: las actividades físicas pueden favorecer la expresión corporal codificada de emociones y de representaciones psicológicas o culturales, que se transforman así en el vector de un mensaje de naturaleza estética (danza, mimo, etc.).

En definitiva, así concebida, la EF pasa a ser una escuela de la acción y de la decisión.

\section{LA IMPORTANCIA DE LA LÓGICA INTERNA}

Para el docente de EF, se tratará de implementar las situaciones motrices que mejor permitan al niño tomar conciencia de sus recursos, dominar sus conductas, llegar a ser autónomo. Para ello, el docente deberá organizar situaciones motrices cuya lógica interna esté en adecuación con sus objetivos pedagógicos y sus finalidades educativas.

¿Qué hay que entender por «lógica interna»? Se trata de las características fundamentales de las conductas motrices de los practicantes, en relación con la pertinencia de la EF; es decir de la relación del practicante:

- con el espacio: con el medio, estable o cambiante, domesticado o salvaje;

- con los objetos: los diferentes accesorios o instrumentos (raqueta, esquís, bicicleta, garrocha, etc.);

- con el tiempo: las duraciones, las sincronizaciones, los cambios a lo largo del tiempo, etc.

- con otro: según las interacciones motrices de cooperación o de oposición, relacionadas con fenómenos de comunicación, de empatía, de pre - acción. La relación puede ser agresiva y violenta o simpática y amistosa.

Esta lógica interna de las situaciones motrices es elegida por el docente que organiza el entorno, propone accesorios, distribuye a los practicantes y da consignas de uso y de acción. De este modo induce un tipo de lógica interna preciso: práctica psicomotriz o sociomotriz, actividad de cooperación o de oposición, oposición a distancia o cuerpo a cuerpo, acción en un medio estandarizado o en un medio imprevisible, etc. En el caso de los juegos tradicionales y de los deportes, los sistemas de reglas son los que van a determinar la lógica interna que deberán cumplir las conductas motrices de los jugadores. 


\section{LOS DOMINIOS DE ACCIÓN MOTRIZ}

La acción motriz de los practicantes va a estar sometida a las imposiciones de la lógica interna de las situaciones propuestas: ejercicios didácticos, juegos tradicionales, prácticas "libres" en un medio ambiente determinado, deportes, etc. Por lo tanto es importante identificar "dominios de acción", es decir campos de prácticas cuyas lógicas internas tienen características relativamente similares. Dichos dominios de acción motriz agrupan actividades cuya influencia educativa es globalmente semejante. Este proceso brinda como resultado una clasificación que instala una coherencia y una inteligibilidad en todo el conjunto de las actividades físicas y deportivas. Además, esta clasificación provee una herramienta para organizar y planificar la enseñanza de la EF.

Se constata así que la praxiología motriz clarifica a la EF tanto en su concepción general como en sus intervenciones específicas. Por ejemplo, la noción de esquema corporal ha podido ser reinterpretada: la lógica interna de cada situación motriz influye en la representación dinámica del cuerpo que está involucrado, afectiva o cognitivamente, en el juego de exigencias particulares a cada práctica. De ello se desprende que hay tantos "esquemas corporales" como situaciones motrices diferentes. Esto es lo que muestra la investigación presentada por Luc Collard (2011) basada en el análisis de los dibujos de los niños que se representan practicando diferentes actividades ${ }^{2}$.

La identificación de los dominios de acción es de vital importancia, ya que hará particularmente inteligible la organización general de la $E F$, y permitirá adaptarla a las características de las clases y de los alumnos.

Se diferenciará por ejemplo el campo de las actividades sociomotrices y el campo de las actividades psicomotrices. Entre las primeras, se distinguirán las situaciones de oposición de las situaciones de cooperación motrices; entre las segundas, se separarán las situaciones en medio estandarizado desprovisto de incertidumbre, de las situaciones en un medio cargado de imprevistos. A todas estas diferencias de lógica interna corresponden diferencias de efecto educativo. El docente de EF debe estar informado de estas influencias muy disímiles, que son puestas en evidencia por la praxiología motriz, y que se encuentran en las bases del proceso educativo.

La praxiología motriz no se confunde con la EF, pero puede arrojar luz respecto a su coherencia global, a los mecanismos de funcionamiento, a la

\footnotetext{
2 Nota del Revisor: el autor del artículo hace referencia a la exposición oral de Luc Collard titulada "Esquemas corporales y dominios de la acción motriz", que tuvo lugar en el marco del XIV Seminario Internacional y II Latinoamericano de Praxiología Motriz: Educación Física y contextos críticos, realizado en 2011 en la UNLP -Argentina-. Ver programa completo del evento en: http://seminprax.fahce.unlp.edu.ar/programa
} 
adecuación de las prácticas a los efectos educativos buscados. La praxiología no trata de imponer normas o finalidades particulares, mientras que la EF busca explícitamente efectos educativos demostrables. La EF es normativa mientras que la praxiología, como toda disciplina científica, no lo es.

De lo expuesto surge la necesidad de realizar una constante ida y vuelta entre la reflexión teórica y la realización práctica. Esta asociación profunda entre la teoría y la práctica es el secreto de los futuros avances en EF y en praxiología motriz. Por ello es necesario proponer a la praxiología motriz como eje vertebral de la formación de los futuros docentes de EF.

\section{AGRADECIMENTOS}

A la Doctora Ana María Gentile por la cuidadosa traducción del original en francés a la versión en español, y al Doctor Jorge Ricardo Saraví por la revisión técnica de la traducción. También el agradecimiento a los editores de la revista y a los coordinadores del Dossier, por el apoyo brindado para esta publicación.

\section{REFERÊNCIAS}

BOURDIEU, Pierre. La distinción. Criterio y bases sociales del gusto. Madrid: Editorial Taurus. 1988.

FOUCAULT, Michel. Vigilar y castigar. México: Siglo XXI, 1996.

DURING, Bertrand. La crisis de las pedagogias corporales. Málaga: Edición UNISPORT, 1992.

LAGARDERA, Francisco Otero. Por una educación física sostenible para el siglo XXI: La pedagogía de las conductas motrices. In: Actas del XIV Seminario Internacional de Praxiología Motriz. Educación Física y contextos críticos, 12 al 15 de octubre de 2011, La Plata, Argentina. Disponible en:

http://www.memoria.fahce.unlp.edu.ar/trab eventos/ev.1418/ev.1418.pdf

LAVEGA BURGUÉS, Pere. Dominios de acción motriz y afectividad. In: Actas del XIV Seminario Internacional de Praxiología Motriz. Educación Física y contextos críticos, 12 al 15 de octubre de 2011, La Plata, Argentina. Disponible en:

http://www.memoria.fahce.unlp.edu.ar/trab eventos/ev.1413/ev.1413.pdf

MERLEAU-PONTY, Maurice. Fenomenología de la percepción. Madrid: Editorial Planeta-De Agostini, 1993.

PARLEBAS, Pierre. Contribution à un lexique commenté en science de l'action motrice. París: Edición del INSEP, 1981.

PARLEBAS, Pierre. Juegos, deportes y sociedad. Léxico de praxiología motriz. Barcelona: Editorial Paidotribo, 2001. 